\title{
The significance of anthocyanins in the prevention and treatment of type 2 diabetes
}

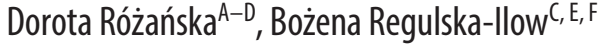 \\ Department of Dietetics, Wroclaw Medical University, Poland \\ A - research concept and design; B - collection and/or assembly of data; $C$ - data analysis and interpretation; \\ $\mathrm{D}$ - writing the article; $\mathrm{E}$ - critical revision of the article; $\mathrm{F}$ - final approval of the article
}

\section{Address for correspondence \\ Dorota Różańska}

E-mail: dorota.rozanska@umed.wroc.pl

\section{Funding sources}

None declared

\section{Conflict of interest}

None declared

Received on May 14, 2016

Reviewed on June 19, 2016

Accepted on September 2, 2016

\begin{abstract}
Anthocyanins are food compounds which belong to polyphenols and can mainly be found in dark fruits (e.g., blueberries, black currants, cranberries) and vegetables (e.g. red cabbage, radish, eggplant). The results of large research have shown that these compounds play an important role in the prevention of type 2 diabetes (T2D). In rodent studies and in studies with isolated omental adipocytes, it was observed that anthocyanins regulated the carbohydrate metabolism in the body due to the upregulation of GLUT4 (insulinregulated glucose transporter) translocation, increased activation of PPARY (peroxisome proliferator-activated receptor-y) in adipose tissue and skeletal muscles as well as increased secretion of adiponectin and leptin. Moreover, these compounds reduced the inflammation status in the body. Studies conducted on humans and experimental animals showed that anthocyanins decrease insulin resistance. This effect may be achieved by the upregulation of GLUT4 gene expression, activation of AMP-activated protein kinase and downregulation of retinol binding protein 4 (RBP4) expression. Anthocyanins also increased the uptake and utilization of glucose by tissues in streptozotocin-induced diabetic rats and mice, and they also protected pancreatic cells against necrosis induced by streptozotocin. Another mechanism that might explain the lower glucose level in the blood after a meal with anthocyanins compared to a meal without them is the inhibition of intestinal a-glucosidase and pancreatic a-amylase by these compounds. Moreover, anthocyanins improve insulin secretion, which can have a special meaning for people with T2D. The evidence from the presented studies suggests that foods rich in anthocyanins may be one of the diet elements supporting the prevention and treatment of T2D.
\end{abstract}

Key words: insulin resistance, type 2 diabetes, anthocyanins, postprandial glycemia, cyanidin-3-0-glucoside

DOI

$10.17219 /$ acem $/ 64983$

\section{Copyright}

Copyright by Author(s)

This is an article distributed under the terms of the

Creative Commons Attribution Non-Commercial License

(http://creativecommons.org/licenses/by-nc-nd/4.0/) 


\section{Background}

Flavonoids are a numerous group of plant compounds that cannot be synthesized in the human body. Their main chemical structure consists of phenolic and pyrane rings. The variety of flavonoids is determined by the type of substituent, the number of hydroxyl and methoxyl groups in the molecule, and the location of its addition. Flavonoids exhibit antioxidant, antiradical and chelating abilities. These compounds are usually responsible for the color and flavor of plant foods. Moreover, they prevent fat oxidation and protect vitamins and enzymes. In plants, these compounds occur mainly as glycosides. ${ }^{1-3}$

One of the subclasses of flavonoids are anthocyanins. Among these compounds there are: cyanidin, delphinidin, malvidin, pelargonidin, peonidin, and petunidin. The chemical structure of anthocyanins is presented in Fig. 1. These compounds have 4, 5 or 6 hydroxyl groups in the molecule, while some of them have a methoxyl group in chain B. ${ }^{4}$

The main source of anthocyanins are dark fruits such as blackberries, blueberries, cranberries, black and red currants, red grapes, raspberries, and vegetables such as red cabbage and radish, but also some types of nuts and red wine. ${ }^{4}$ The content of these compounds in selected food products is presented in Table 1 .

An association between a higher intake of total flavonoids, or their subclasses, and a lower risk of hypertension, myocardial infarction or stroke was found in numerous epidemiological studies. ${ }^{5-7}$ Particularly noteworthy, however, is the role of anthocyanins as dietary components in the protection against the development of type 2 diabetes (T2D). The results of Nurses' Health Study I and II and

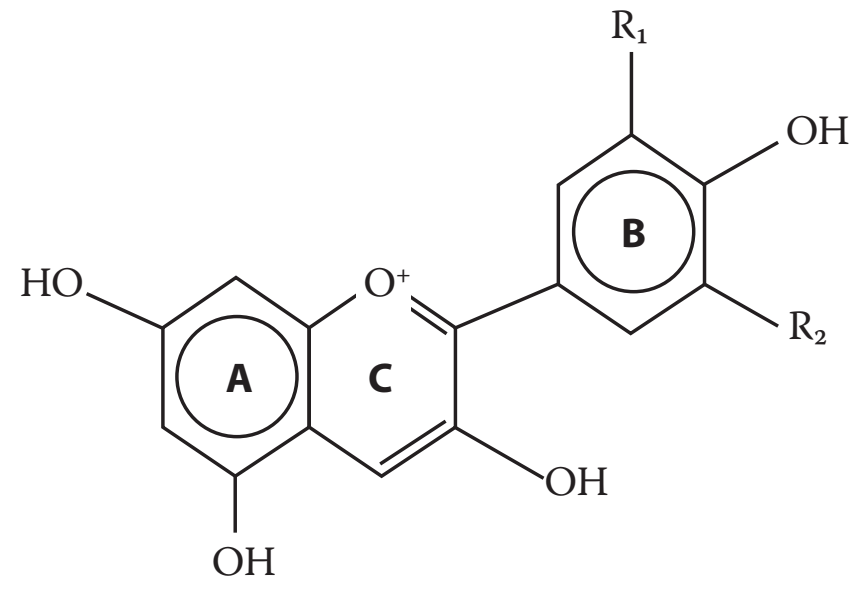

$$
\begin{gathered}
\text { Cyanidin }\left(\mathrm{R}_{1}=\mathrm{H}, \mathrm{R}_{2}=\mathrm{OH}\right) \\
\text { Delphinidin }\left(\mathrm{R}_{1}=\mathrm{R}_{2}=\mathrm{OH}\right) \\
\text { Malvidin }\left(\mathrm{R}_{1}=\mathrm{R}_{2}=\mathrm{OMe}\right) \\
\text { Pelargonidin }\left(\mathrm{R}_{1}=\mathrm{R}_{2}=\mathrm{H}\right) \\
\text { Peonidin }\left(\mathrm{R}_{1}=\mathrm{H}, \mathrm{R}_{2}=\mathrm{OMe}\right) \\
\text { Petunidin }\left(\mathrm{R}_{1}=\mathrm{OH}, \mathrm{R}_{2}=\mathrm{OMe}\right)
\end{gathered}
$$

Fig. 1. Basic structure of anthocyanins ${ }^{4}$
Health Professionals Follow-Up Study showed that a lower risk of T2D was associated with higher anthocyanin content in the diet. ${ }^{8}$

The aim of this study was to review the literature on the importance of anthocyanins in the regulation of the carbohydrate metabolism and reduction of insulin resistance in the body, as major factors decreasing the risk of type 2 diabetes.

\section{Insulin resistance}

Weakening the sensitivity of cells to insulin is one of the factors contributing to the development of T2D. In the development of insulin resistance, many mechanisms associated with improper functioning of some enzymes and hormones may be involved. An increased risk of insulin resistance is related to an excessive level of visceral fat in the body, which leads to the dysregulation of the carbohydrate metabolism, a decrease in insulin sensitivity of tissues, the development of hyperglycemia and inflammatory status and, as a consequence, an increased risk of developing T2D. Adipocytes of visceral fat are metabolically active. They secrete, among others, hormones such as adiponectin, leptin, resistin, and proinflammatory cytokines such as TNF- $\alpha$ (tumor necrosis factor) or IL-6 (interleukin-6). ${ }^{9}$

Scazzocchio et al. analyzed the influence of cyanidin3-O- $\beta$-glucoside (C3G) and metabolite protocatechuic acid (PCA) on the activation of glucose transport in human omental adipocytes and mice cells (3T3-L1). ${ }^{10}$ Initially, the cells were incubated with oxidized LDL (oxLDL), which caused a decrease in glucose uptake by $40 \%$ and a decrease in GLUT4 (insulin-regulated glucose transporter) concentration by $60 \%$. After that, the cells were treated with $50 \mu \mathrm{mol} / \mathrm{L}$ C3G and $100 \mu \mathrm{mol} / \mathrm{L}$ PCA. It was then observed how these compounds affected the uptake of $\left[{ }^{3} \mathrm{H}\right]$-2-deoxyglucose, GLUT4 translocation, secretion of adiponectin, and activation of peroxisome proliferatoractivated receptor- $\gamma$ (PPAR- $\gamma$ ), which participate in adipocyte differentiation and maturation, and increased insulin sensitivity. Both of the studied phenolic compounds counteracted the decline in glucose uptake and reversed defective GLUT4 translocation in cells treated and not treated with insulin. C3G and PCA overcame the negative influence of oxLDL on mRNA PPAR- $\gamma$ expression and PPAR- $\gamma$ activity. The beneficial effect of anthocyanins on PPAR activity in adipose tissue and skeletal muscles was also observed by other authors in a study conducted on rats. ${ }^{11}$

Tsuda et al. also found anthocyanins to be compounds that might be of importance in T2D prevention. ${ }^{12}$ A study on isolated rat adipocytes demonstrated enhanced adiponectin and leptin secretion, in cells treated with cyanidin. Moreover, increased concentration of adiponectin mRNA in white adipose tissue was observed in rats after 12 weeks of being fed a diet enriched with C3G, 
as compared to the control group. Low levels of adiponectin in the serum of people with T2D correlates with insulin resistance and decreased insulin sensitivity. ${ }^{13-15}$ Adiponectin regulates glucose homeostasis in an organism through many mechanisms in adipose tissue, e.g., in the pancreas and the liver. It also prevents apoptosis in INS-1 $\beta$ cells, which promotes proper insulin secretion by the pancreas. ${ }^{15}$ Leptin is a hormone which takes part in the regulation of food intake by reducing appetite, thereby reducing body weight gain, but its activity in obese people is usually limited. However, in studies conducted on diabetic people without obesity, leptin significantly enhanced insulin sensitivity, improved glycemic control and reduced triglyceride concentration in the blood and adipose tissue. Moreover, treatment with leptin caused a mild reduction of blood glucose level without causing hypoglycemia. ${ }^{16}$ Liu et al. proved that C3G increased serum adiponectin concentrations in diabetic mice, which also improved the endothelial function, thereby reducing the risk of developing a cardiovascular disease. ${ }^{17}$

In mice fed with a high-fat diet (60\% energy from fats) there was observed an increase in the expression of inflammatory markers such as TNF- $\alpha$, IL-6, MCP-1 (monocyte chemoattractant protein 1), iNOS (inducible nitric oxide synthase), and increased oxidative stress. ${ }^{18}$ In mice fed with a high-fat diet supplemented with blueberry powder (31.44 g of anthocyanins/1 kg dry weight), such irregularities were not noticed. Also in a randomized, single-blind, placebocontrolled crossover trial, conducted on a group of overweight and obese people, it was found that anthocyanins from strawberries decreased the inflammatory status (defined as C-reactive protein and IL-6 levels) after a meal rich in carbohydrates, with moderate fat content. ${ }^{19}$

A randomized, double-blind, placebo-controlled study showed that anthocyanin supplementation reduced fasting plasma glucose levels and decreased insulin resistance in diabetic patients. The beneficial effect of these compounds was associated, among others, with enhanced adiponectin synthesis. In addition, patients in the anthocyanin group showed higher $\beta$-hydroxybutyrate concentrations compared to the placebo group, though still in the normal range, implying an increase in total body energy expenditure. This, however, did not increase the risk of ketoacidosis in diabetic patients. ${ }^{20}$ Other authors explain that $\beta$-hydroxybutyrate decreases the risk of insulin resistance by, among others, reducing the glycation of insulin and reducing the generation of insulin advanced glycation end products. $^{21}$

The authors of another randomized, double-blind, placebo-controlled clinical trial analyzed the influence of supplementation with bioactives from blueberries on whole-body insulin sensitivity in obese (insulin resistant and nondiabetic) adults. After 6 weeks of study, the supplemented group showed increased insulin sensitivity compared

Table 1. The content of anthocyanins in selected food products $[\mathrm{mg} / 100 \mathrm{~g}]^{4}$

\begin{tabular}{|c|c|c|c|c|c|c|c|}
\hline Product & Cyanidin & Delphinidin & Malvidin & Pelargonidin & Peonidin & Petunidin & Total \\
\hline Blackberries & 99.95 & 0.0 & 0.0 & 0.45 & 0.21 & 0.0 & 100.61 \\
\hline Blueberries & 8.46 & 35.43 & 67.59 & 0.0 & 20.29 & 31.53 & 163.30 \\
\hline Cherries & 32.57 & nd & nd & nd & 0.87 & nd & 33.44 \\
\hline Cranberries & 46.43 & 7.67 & 0.44 & 0.32 & 49.16 & 0.0 & 104.02 \\
\hline Black currants & 62.46 & 89.62 & nd & 1.17 & 0.66 & 3.87 & 157.78 \\
\hline Red currants & 65.54 & 9.32 & nd & nd & 0.16 & nd & 75.02 \\
\hline Red grapes & 1.16 & 2.27 & 39.00 & 0.02 & 3.62 & 1.97 & 48.04 \\
\hline Raspberries & 45.77 & 1.32 & 0.13 & 0.98 & 0.12 & 0.31 & 48.63 \\
\hline Strawberries & 1.68 & 0.31 & 0.01 & 24.85 & 0.05 & 0.11 & 27.01 \\
\hline Gooseberries & 8.73 & 0.01 & nd & nd & 0.77 & nd & 9.51 \\
\hline Apples & 1.57 & 0.0 & 0.0 & 0.0 & 0.02 & 0.0 & 1.59 \\
\hline Bananas & 0.0 & 7.39 & 0.0 & 0.0 & 0.0 & 0.0 & 7.39 \\
\hline Red cabbage & 209.83 & 0.10 & nd & 0.02 & nd & nd & 209.95 \\
\hline Radish & 0.0 & 0.0 & 0.0 & 63.13 & 0.0 & 0.0 & 63.13 \\
\hline Eggplant & nd & 85.69 & nd & nd & nd & nd & 85.69 \\
\hline Red onion & 3.19 & 4.28 & nd & 0.02 & 2.07 & nd & 9.56 \\
\hline Beans (black, mature seeds, raw) & nd & 18.50 & 10.61 & nd & nd & 15.41 & 44.52 \\
\hline Almonds & 2.46 & 0.0 & 0.0 & 0.0 & 0.0 & 0.0 & 2.46 \\
\hline Pistachios & 7.33 & 0.0 & 0.0 & 0.0 & 0.0 & 0.0 & 7.33 \\
\hline Red wine (Cabernet Sauvignon) & nd & 4.18 & 26.24 & nd & 1.85 & 3.32 & 35.59 \\
\hline Red wine (sweet) & nd & 3.90 & 94.83 & nd & 3.93 & 6.63 & 109.29 \\
\hline
\end{tabular}


to the placebo group. ${ }^{22}$ Jennings et al. observed an improvement in insulin resistance related to a higher intake of foods rich in anthocyanins and flavones. ${ }^{23}$ The effect of anthocyanins on improving insulin resistance may be associated, among others, with the upregulation of GLUT4 gene expression, as was found for C3G. ${ }^{24}$

The authors of the rodent studies explained the amelioration of insulin sensitivity through anthocyanins activating AMP-activated protein kinase (AMPK), which stimulated glucose uptake and insulin secretion by pancreatic $\beta$ cells. Among others, the activation of AMPK was accompanied by upregulation of GLUT4 in white adipose tissue and skeletal muscles, and downregulation of gluconeogenesis in the liver. ${ }^{25,26}$ The activation of AMPK is associated with the phosphorylation of Thr172 in the activation loop of AMPK. ${ }^{27}$ After 3-5 weeks, the diabetic mice fed with a diet consisting of anthocyanin-rich bilberry extract had significantly lower blood glucose levels than mice from the control group. The effect of decreasing glucose level in the blood after $30 \mathrm{~min}, 90 \mathrm{~min}$ and $120 \mathrm{~min}$ of insulin injection was significantly greater in the study group compared to the control. The mice fed with a high anthocyanin diet, as compared to the control group, had increased total AMPK $\alpha$ and phosphorylation of AMPK $\alpha$ at Thr172 in white adipose tissue. Increased phosphorylation of AMPK $\alpha$ was also observed in skeletal muscles and the liver. ${ }^{25}$ Tsuda et al. also observed increased phosphorylation of AMPK $\alpha$ at Thr172 in rat adipose cells treated with cyanidin and C3G, as compared to the control group. ${ }^{12}$ The gene expression level of GLUT4, both in white adipose tissue and in skeletal muscles, was significantly higher in mice fed with a diet consisting of anthocyanin-rich bilberry extract compared to the control group. On the other hand, there were no differences between the groups in the gene expression level of adiponectin and adiponectin receptors (Adipo $\mathrm{R}_{1}$ and $\mathrm{R}_{2}$ ) in the liver and skeletal muscles, the concentration of adiponectin in serum, the levels of tyrosine phosphorylation of insulin receptor substrate-1 (IRS-1) and serine phosphorylation of Akt (the phosphoprotein:total protein ratio) in the liver, skeletal muscles and white adipose tissue. ${ }^{25}$ Kurimoto et al. also found increased insulin sensitivity and reduced hyperglycemia in diabetic mice due to the activation of AMPK, after a diet supplemented with black soybean seed coat extract, rich in anthocyanins. ${ }^{26}$

Sasaki et al. suggest another mechanism that can explain why anthocyanins may reduce hyperglycemia and improve insulin sensitivity. ${ }^{28}$ They analyzed the influence of C3G on retinol binding protein 4 (RBP-4) expression in a study conducted on diabetic mice. RBP-4 is an adipokine; its higher concentration is correlated with insulin resistance. Diabetic mice were fed a control diet or a control $+0.2 \%$ C3G diet. At the beginning of the study, mice from the control group and C3G group had similar glucose levels in serum. After 3 weeks, the animals from the treatment group had significantly lower fasting glucose in serum compared to the control group (300.1 md/dL vs $393.9 \mathrm{mg} / \mathrm{dL}$ ), and the difference persisted after further 2 weeks of study (356.5 mg/dL vs $454.2 \mathrm{mg} / \mathrm{dL}$ ). The amelioration of insulin sensitivity was also observed in mice from the treatment group. These changes were not associated with the expression of adiponectin and its receptors. However, it was found that C3G significantly upregulated GLUT4 and downregulated RBP-4 in white adipose tissue. ${ }^{28}$

Seymour et al. observed the beneficial impact of blueberry extract on reducing insulin resistance and fasting insulin levels in obese rats. ${ }^{11}$ These effects were related to enhanced adipose and skeletal muscle PPAR activity.

De Furia et al. conducted a study on mice, which were divided into 3 groups and fed for 8 weeks with 3 types of diet: A - low-fat (10\% of energy from fats); B - high-fat (60\% of energy from fats); and C - high-fat with $4 \%$ extract from blueberries. ${ }^{18}$ The mice from group $\mathrm{C}$ had significantly lower insulin resistance than the mice from group $B$, and similar to that observed in group A. It was noted that the increase in insulin resistance was accompanied by the death of adipocytes, which was offset by the berry extract. Moreover, in the mice from group B, compared to C, increased M1-polarized adipose tissue macrophages (CD11c+) were observed, which is considered a marker of human insulin resistance..$^{18,29}$

Other authors also proved the protective role of anthocyanins with regard to insulin resistance. ${ }^{30}$ The $1^{\text {st }}$ group of rats was fed with a high-fructose diet $(630 \mathrm{~g} / \mathrm{kg})$, while the $2^{\text {nd }}$ was fed with a high-fructose diet with an anthocyanin-rich extract from black rice $(5 \mathrm{~g} / \mathrm{kg}$ high-fructose diet). After 4 weeks, rats from the $2^{\text {nd }}$ group had lower insulin resistance compared to those from the $1^{\text {st }}$ group. At a further stage of the study, rats with established insulin resistance were treated with the anthocyanin-rich extract in the amount of $5 \mathrm{~g} / 1 \mathrm{~kg}$ high-fructose diet or with pioglitazone (a drug that increases insulin sensitivity, reduces insulin resistance in adipose tissue, skeletal muscle and the liver, decreases the concentration of free fatty acids and glucose in the blood) at an amount of $270 \mathrm{mg} / 1 \mathrm{~kg}$ highfructose diet. Both of these therapies reduced glucose intolerance, but only pioglitazone reversed the fructoseinduced hyperinsulinemia.

The results of the presented studies are summarized in Table 2.

\section{Postprandial glycemia}

Anthocyanins were analyzed in view of their importance in the regulation of postprandial glycemia. Törrönen et al. conducted a study among healthy adult volunteers to assess the influence of berries on the postprandial plasma glucose response to sucrose. ${ }^{31}$ The study group consumed a purée made of bilberries, blackcurrants, cranberries, strawberries and $35 \mathrm{~g}$ of sucrose, while the control group only sucrose. Plasma glucose concentration in the study group at $15 \mathrm{~min}$ and $30 \mathrm{~min}$ after a meal was significantly lower than in the control group, while at $150 \mathrm{~min}$ it was 
significantly higher. At $3 \mathrm{~h}$ after a meal there was no difference in plasma glucose between the groups. The maximum plasma glucose concentration was reachedat $45 \mathrm{~min}$ after the berry meal and at $30 \mathrm{~min}$ after the sucrose alone. The results of the study indicate reduced absorption of glucose from a meal containing berries, and a consequent delay in glycemic response after a meal. Similar results were also observed in a later study, where the effects of $35 \mathrm{~g}$ of sucrose consumption with blackcurrants, lingonberries and berry nectars on postprandial glucose and insulin were investigated. ${ }^{32}$ Volunteers who consumed sugar with fruits, compared to those who consumed sugar alone, had lower glucose and insulin concentrations during the first $30 \mathrm{~min}$, and a slower decline during the following $90 \mathrm{~min}$. Thereby, improved glycemic response prevented a hypoglycemic state in volunteers from groups which were given fruits or nectar.

Törrönen et al. also investigated the effects of different berries consumed with wheat bread or rye bread on postprandial glucose in healthy women. ${ }^{33}$ After the volunteers consumed wheat bread with a fruit mixture (strawberries, bilberries, cranberries, blackcurrants), the $0-30 \mathrm{~min}$ area under their blood glucose curve (AUC) was decreased by $32 \%$ in comparison to AUC after wheat bread

Table 2. Results of the selected studies on the role of anthocyanins in the prevention of type 2 diabetes

\begin{tabular}{|c|c|c|c|}
\hline No. & Anthocyanin/product tested & Mechanism of action & Ref. \\
\hline 1 & C3G and PCA & $\begin{array}{l}\text { improved GLUT4 translocation, secretion of adiponectin and activation of PPAR- } \gamma \text {; } \\
\text { counteracted decline in glucose uptake }\end{array}$ & 10 \\
\hline 2 & Blueberry extract & $\begin{array}{l}\text { reduced insulin resistance and fasting insulin levels in obese rats; enhanced adipose and } \\
\text { skeletal muscle PPAR activity }\end{array}$ & 11 \\
\hline 3 & Cyanidin & $\begin{array}{l}\text { enhanced adiponectin and leptin secretion; increased phosphorylation of AMPKa } \\
\text { at Thr172 in rat adipose cells }\end{array}$ & 12 \\
\hline 4 & Blueberry powder & reduced insulin resistance, inflammatory marker expression and oxidative stress & 18 \\
\hline 5 & Anthocyanins from strawberries & decreased inflammatory status & 19 \\
\hline 6 & Anthocyanins from blueberries & increased insulin sensitivity in obese adult subjects (insulin resistant and nondiabetic) & 22 \\
\hline 7 & Food rich in anthocyanins & improved insulin resistance & 23 \\
\hline 8 & C3G & upregulated GLUT4 gene expression & 24 \\
\hline 9 & Anthocyanin-rich bilberry extract & $\begin{array}{l}\text { increased total AMPKa and phosphorylation of AMPKa at Thr172 in white adipose tissue; } \\
\text { increased phosphorylation of AMPKa in skeletal muscles and the liver; enhanced gene } \\
\text { expression level of GLUT4; ameliorated insulin sensitivity }\end{array}$ & 25 \\
\hline 10 & Black soybean seed coat extract & $\begin{array}{l}\text { increased insulin sensitivity and reduced hyperglycemia in diabetic mice due to the activation } \\
\text { of AMPK }\end{array}$ & 26 \\
\hline 11 & $\mathrm{C} 3 \mathrm{G}$ & $\begin{array}{l}\text { ameliorated insulin sensitivity; upregulated GLUT4 and downregulated RBP-4 in white adipose } \\
\text { tissue }\end{array}$ & 28 \\
\hline 12 & $\begin{array}{l}\text { Anthocyanin-rich extract from } \\
\text { black rice }\end{array}$ & reduced insulin resistance & 30 \\
\hline 13 & $\begin{array}{l}\text { Purée made of bilberries, } \\
\text { blackcurrants, cranberries, } \\
\text { strawberries }\end{array}$ & reduced absorption of glucose and delay in glycemic response after a meal & 31 \\
\hline 14 & $\begin{array}{l}\text { Fruit mixture (strawberries, } \\
\text { bilberries, cranberries, } \\
\text { blackcurrants) }\end{array}$ & $\begin{array}{l}\text { decreased area under the blood glucose curve (AUC) after the consumption of bread with } \\
\text { fruits compared to bread alone; improved glycemic profile }\end{array}$ & 33 \\
\hline 15 & $\begin{array}{l}\text { Black soybean seed coat extract } \\
\text { (C3G, delphinidin-3-glucoside, } \\
\text { petunidin-3-glucoside) }\end{array}$ & $\begin{array}{l}\text { reduced blood glucose level in diabetic rats; increased expression and translocation of GLUT4; } \\
\text { activated insulin receptor phosphorylation; increased uptake and utilization of glucose } \\
\text { by cells; prevention of streptozotocin-induced apoptosis in pancreatic cells }\end{array}$ & 35 \\
\hline 16 & $\mathrm{C} 3 \mathrm{G}$ & $\begin{array}{l}\text { prevention of pancreatic cell death; decreased mitochondrial production of ROS; increased } \\
\text { IGF-II, gene transcript levels and insulin protein in INS-1 cells }\end{array}$ & 36 \\
\hline 17 & Cyanidin-3-rutinoside & a-glucosidase inhibition & 37 \\
\hline 18 & Cyanidin and its glycosides & $\begin{array}{l}\text { intestinal sucrose inhibition: cyanidin-3-galactoside > C3G > cyanidin > cyanidin-3.5- } \\
\text { diglucosides; C3G - the most effective inhibitor for pancreatic a-amylase }\end{array}$ & 38 \\
\hline 19 & $\begin{array}{l}\text { Cyanidin-diglucoside and } \\
\text { pelargonidin-3-rutinoside }\end{array}$ & inhibitors for a-glucosidases, but not for pancreatic a-amylase and lipase & 39 \\
\hline 20 & $\begin{array}{l}9 \text { anthocyanin compounds } \\
\text { (glycosides and aglycones) }\end{array}$ & $\begin{array}{l}\text { stimulation of insulin secretion with } 4 \text { mM glucose concentration: delphinidin-3- } \\
\text { glucoside > cyanidin > pelargonidin > delphinidin > C3G; } \\
\text { stimulation of insulin secretion with } 10 \text { mM glucose concentration: C3G > delphinidin-3- } \\
\text { glucoside > cyanidin-3-galactoside > pelargonidin-3-galactoside > cyanidin }\end{array}$ & 40 \\
\hline
\end{tabular}

C3G - cyanidin-3-O- $\beta$-glucoside; PCA - protocatechuic acid; PPAR- - - peroxisome proliferator-activated receptor- $\gamma$; AMPKa - AMP-activated protein kinase; RBP-4 - retinol binding protein 4; ROS - reactive oxygen species; IGF-II - insulin-like growth factor II. 
consumption, and by $27 \%$ in comparison to AUC after rye bread consumption. A significant improvement in glycemic profile (the time [min] during which the plasma glucose was above the fasting concentration divided by the incremental peak glucose value $[\mathrm{mmol} / \mathrm{L}])$ was observed after wheat bread consumption with strawberries and fruit mixture (by 36\% and 38\%, respectively) and after rye bread consumption with fruit mixture (by 19\%) in comparison to glycemic profile after the consumption of bread without fruits.

Jayaprakasam et al. showed that anthocyanins extracted from Cornelian cherries amend glucose tolerance in mice. ${ }^{34}$ The $1^{\text {st }}$ group of mice was fed a high-fat diet (60\% energy from fats), the $2^{\text {nd }}$ was fed a high-fat diet supplemented with an extract from Cornelian cherries (1 g of anthocyanins $/ 1 \mathrm{~kg}$ high-fat diet), and the $3^{\text {rd }}$ was fed a high-fat diet supplemented with ursolic acid, which demonstrates potential anti-diabetic properties $(500 \mathrm{mg} / 1 \mathrm{~kg}$ high-fat diet). The control group was fed a standard rodent diet $(10 \%$ energy from fats). A glucose tolerance test was performed after 6 weeks. The results showed that both anthocyanins and ursolic acid significantly improved glucose tolerance compared to a high-fat diet alone.

The results of another study proved that anthocyanins may also play a role in the regulation of the plasma glucose level in streptozotocin-induced diabetic rats. ${ }^{35}$ The diet used in this study contained black soybean seed coat extract $(50 \mathrm{mg} / \mathrm{kg})$, which consisted of cyanidin-3-glucoside (72\%), delphinidin-3-glucoside (20\%) and petunidin-3-glucoside (6\%). It was observed that anthocyanins significantly reduced the blood glucose level in diabetic rats. Anthocyanins also increased the expression and translocation of GLUT4 as well as enhanced the activation of the insulin receptor phosphorylation, thereby increasing the uptake and utilization of glucose by cells. It was also found that anthocyanins may prevent streptozotocin-induced apoptosis in pancreatic cells. Sun et al. conducted a study on streptozotocin-induced diabetic mice. ${ }^{36}$ The authors observed that C3G had a protective effect on pancreatic cells by preventing their death, increasing cellular viability and decreasing the mitochondrial production of reactive oxygen species. Chinese bayberry extract, rich in C3G, improved glucose tolerance in diabetic mice. This extract also caused an increase in insulin-like growth factor II (IGF-II), gene transcript levels and insulin protein in INS-1 cells. ${ }^{36}$

Other mechanisms that may explain lower blood glucose level after a meal with anthocyanins compared to a meal without these compounds is the inhibition of intestinal $\alpha$-glucosidase and pancreatic $\alpha$-amylase ${ }^{37-39}$ The effectiveness of cyanidin-3-rutinoside (C3R) in $\alpha$-glucosidase inhibition was observed in a study on normal rats with an oral maltose and sucrose tolerance test. Moreover, C3R exhibited a synergistic effect with acarbose, used in the treatment of T2D. ${ }^{37}$ Akkarachiyasit et al. showed that cyanidin and its glycosides are more specific inhibitors of intestinal sucrase than maltase. ${ }^{38}$ The highest inhibition activity against intestinal sucrose was shown with cyanidin-3-galactoside, followed by C3G, cyanidin and cyanidin-3.5-diglucosides. Cyanidin glucosides also exhibited a synergistic effect with acarbose in the inhibition of sucrase and maltase, but such an effect was not observed for cyanidin aglycon. C3G was the most effective inhibitor for pancreatic $\alpha$-amylase, while cyanidin3-galactoside and cyanidin-3.5-diglucosides were not so powerful. The results of the study also showed a synergistic inhibition for a combination of cyanidin or C3G with acarbose against $\alpha$-amylase. Zhang et al., however, found, that anthocyanins are inhibitors for $\alpha$-glucosidases, but not for pancreatic $\alpha$-amylase and lipase. ${ }^{39}$ The most effective were cyanidin-diglucoside and pelargonidin-3-rutinoside as well as 2 other polyphenol compounds - catechin and ellagic acid.

The results of the selected studies discussed above are presented in Table 2.

\section{Postprandial insulin secretion}

Törrönen et al. conducted a study on a group of healthy women to investigate the effects of different berries consumed with wheat bread or rye bread on postprandial insulin. ${ }^{33}$ The $0-60 \mathrm{~min}$ area under the insulin curve (AUC) after wheat bread consumption with strawberries and chokeberries, in comparison to AUC after wheat bread consumption alone, was decreased by $24 \%$, while with bilberries and lingonberries, AUC decreased by $19 \%$ and $20 \%$, respectively. However, raspberries and cloudberries did not exhibit such effects. After the consumption of wheat or rye bread with a fruit mixture (strawberries, bilberries, cranberries, blackcurrants), the 0-60 min AUC was decreased by $25 \%$ in comparison to the consumption of bread alone. Moreover, a lower insulin level in the blood was observed at $15 \mathrm{~min}$ and $30 \mathrm{~min}$ after a meal, but higher at $120 \mathrm{~min}$ after wheat or rye bread consumption with a fruit mixture in comparison to the consumption of bread alone. Edirisinghe et al. showed decreased insulin levels in the blood at $60 \mathrm{~min}$ and $180 \mathrm{~min}$ after the consumption of a beverage rich in anthocyanins (containing a strawberry extract) compared to the placebo. ${ }^{19}$

Other authors in an in vitro study investigated the influence of 9 compounds (glycosides and aglycones) on insulin secretion by rodent pancreatic $\beta$ cells (INS-1 832/13) treated with $4 \mathrm{mM}$ and $10 \mathrm{mM}$ glucose concentrations. ${ }^{40}$ The most effective in the stimulation of insulin secretion with $4 \mathrm{mM}$ glucose concentration was delphinidin-3-glucoside (1.8-fold increase in insulin secretion) followed by: cyanidin, pelargonidin, delphinidin, and C3G (a 1.5-, 1.4-, 1.3-, and 1.3-fold increase in insulin secretion, respectively). C3G was also tested in different concentrations of the compound investigated and, interestingly, the stimulation of insulin secretion was not related to the C3G dose applied $(5,10,50,100$, and $250 \mu \mathrm{g} / \mathrm{mL})$. 
With $10 \mathrm{mM}$ glucose concentration, the highest increase in insulin secretion (1.43-fold) was observed for C3G, followed by: delphinidin-3-glucoside (1.4-fold), cyanidin3-galactoside and pelargonidin-3-galactoside (1.2-fold) and cyanidin (1.1-fold). The influence of cyanidin-3-galactoside and pelargonidin-3-galactoside on insulin secretion with $4 \mathrm{mM}$ glucose concentration was not observed, nor was the influence of malvidin and petunidin with $4 \mathrm{mM}$ and $10 \mathrm{mM}$ glucose concentrations. ${ }^{40}$ The improvement in insulin secretion caused by anthocyanins may have special significance for people with T2D, whose pancreatic activity is damaged and insufficient.

The results of the selected studies presented in this manuscript are summarized in Table 2.

\section{Summary}

Anthocyanins are food compounds which belong to polyphenols and they might have special significance in the prevention of type 2 diabetes. Numerous studies, both with humans and experimental animal subjects, were conducted to explain the mechanisms of anthocyanin function, by which they regulate the carbohydrate metabolism in the body and reduce insulin resistance.

There are many ways in which these compounds interact in the body. Anthocyanins regulate GLUT4 gene expression and translocation, increase the activation of PPAR $\gamma$ in adipose tissue and in skeletal muscles, increase the activation of AMP-activated protein kinase, enhance the secretion of adiponectin and leptin, reduce retinol binding protein 4 expression, and, moreover, are inhibitors for intestinal $\alpha$-glucosidase and pancreatic $\alpha$-amylase. Anthocyanins also improve insulin secretion by rodent pancreatic $\beta$ cells. It was also found that these compounds protect pancreatic cells against necrosis induced by streptozotocin in diabetic rodents. However, it was observed that the individual anthocyanins and their glycosides have different activity. It is, therefore, necessary to include a variety of plant products in the daily diet, because they contain various anthocyanins. For example, blackberries and red cabbage contain mainly cyanidin, eggplant - delphinidin, blueberries and red grapes - malvidin, while radish - pelargonidin.

Currently, there are no recommendations regarding the optimal content of flavonoids and their subclasses in a diet, neither for healthy nor for sick people. However, the results of the presented studies proved a potential beneficial role of anthocyanins in the prevention and treatment of T2D. The sources of these compounds are mainly fruits and vegetables. Therefore, these products should be included in the everyday diet in the amount of at least $600 \mathrm{~g}$, of which approx. 3/4 should be vegetables. An important source of anthocyanins are the following vegetables: red cabbage, eggplant, radish and red onion. These products contain less than $10 \%$ of carbohydrates and, therefore, can be the main vegetables in a diet. The following fruits are an important source of anthocyanins: blueberries, strawberries, raspberries, blackberries, cranberries, gooseberries or cherries, that all of which also contain less than $10 \%$ of carbohydrates and, therefore, can be consumed in the recommended amounts of up to approx. $150 \mathrm{~g} /$ day. Other fruits, such as red grapes, black currants, plums or bananas, are also sources of anthocyanins, but they contain more than $10 \%$ of carbohydrates and, therefore, should be consumed occasionally and in limited quantities.

Although the development of type 2 diabetes may be due to a number of factors, the evidence from the studies presented by many authors, considering the impact of anthocyanins on the regulation of glycemia and reduction of insulin resistance, is worth emphasizing. Therefore, it appears that the consumption of foods rich in these compounds may be included in recommendations as one of the elements supporting the prevention and treatment of type 2 diabetes.

\section{References}

1. El Gharras H. Polyphenols: Food sources, properties and applications: A review. Int J Food Sci Technol. 2009;44:2512-2518.

2. Ross JA, Kasum CM. Dietary flavonoids: Bioavailability, metabolic effects, and safety. Annu Rev Nutr. 2002;22:19-34.

3. Yao LH, Jiang YM, Shi J, et al. Flavonoids in food and their health benefits. Plant Food Hum Nutr. 2004;59:113-122.

4. Bhagwat S, Haytowitz, DB, Holden JM, eds. 2014. USDA Database for the Flavonoid Content of Selected Foods, Release 3.1. U.S. Department of Agriculture, Agricultural Research Service. Nutrient Data Laboratory Home Page: http://www.ars.usda.gov/nutrientdata/flav. Accessed December 29, 2015.

5. Jennings A, Welch AA, Fairweather-Tait SJ, et al. Higher anthocyanin intake is associated with lower arterial stiffness and central blood pressure in women. Am J Clin Nutr. 2012;96:781-788.

6. Cassidy A, Mukamal KJ, Liu L, Franz M, Eliassen AH, Rimm EB. High anthocyanin intake is associated with a reduced risk of myocardial infarction in young and middle-aged women. Circulation. 2013;127:188-196.

7. Hollman PCH, Geelen A, Kromhout D. Dietary flavonol intake may lower stroke risk in men and women. J Nutr. 2010;140:600-604.

8. Wedick NM, Pan A, Cassidy A, et al. Dietary flavonoid intakes and risk of type 2 diabetes in US men and women. Am J Clin Nutr. 2012;95:925-933.

9. Trujillo ME, Scherer PE. Adipose tissue-derived factors: Impact on health and disease. Endocrine Reviews. 2006;27:762-778.

10. Scazzocchio $B$, Varì R, Filesi $C$, et al. Cyanidin-3-O-b-glucoside and protocatechuic acid exert insulin-like effects by upregulating PPARY activity in human omental adipocytes. Diabetes. 2011;60:2234-2244.

11. Seymour EM, Tanone II, Urcuyo-Llanes DE, et al. Blueberry intake alters skeletal muscle and adipose tissue peroxisome proliferatoractivated receptor activity and reduces insulin resistance in obese rats. J Med Food. 2011;14:1511-1518.

12. Tsuda T, Ueno $Y$, Aoki H, et al. Anthocyanin enhances adipocytokine secretion and adipocyte-specific gene expression in isolated rat adipocytes. Biochem Biophys Res Commun. 2004;316:149-157.

13. Abdelgadir M, Karlsson AF, Berglund L, Berne C. Low serum adiponectin concentrations are associated with insulin sensitivity independent of obesity in Sudanese subjects with type 2 diabetes mellitus. Diabetol Metab Syndr. 2013;5:15. doi: 10.1186/1758-5996-5-15

14. Aleidi S, Issa A, Bustanji H, Khalil M, Bustanji Y. Adiponectin serum levels correlate with insulin resistance in type 2 diabetic patients. Saudi Pharm J. 2015;23:250-256.

15. Tao C, Sifuentes A, Holland WL. Regulation of glucose and lipid homeostasis by adiponectin: Effects on hepatocytes, pancreatic $\beta$ cells and adipocytes. Best Pract Res Clin Endocrinol Metab. 2014;28:43-58.

16. Coppari R, Bjørbæk C. The potential of leptin for treating diabetes and its mechanism of action. Nat Rev Drug Discov. 2012;11:692-708. 
17. Liu Y, Li D, Zhang Y, Sun R, Xia M. Anthocyanin increases adiponectin secretion and protects against diabetes-related endothelial dysfunction. Am J Physiol Endocrinol Metab. 2014;306:E975-E988.

18. De Furia J, Bennett G, Strissel KJ, et al. Dietary blueberry attenuates whole-body insulin resistance in high fat-fed mice by reducing adipocyte death and its inflammatory sequelae. J Nutr. 2009;139:1510-1516.

19. Edirisinghe I, Banaszewski K, Cappozzo J, et al. Strawberry anthocyanin and its association with postprandial inflammation and insulin. Br J Nutr. 2011;106:913-922.

20. Li D, Zhang Y, Liu Y, Sun R, Xia M. Purified anthocyanin supplementation reduces dyslipidemia, enhances antioxidant capacity, and prevents insulin resistance in diabetic patients. J Nutr. 2015;145:742-748.

21. Sabokdast M, Habibi-Rezaei M, Moosavi-Movahedi AA, et al. Protection by beta-hydroxybutyric acid against insulin glycation, lipid peroxidation and microglial cell apoptosis. DARU. 2015;23:42. doi: 10.1186/s40199-015-0126-5

22. Stull AJ, Cash KC, Johnson WD, Champagne CM, Cefalu WT. Bioactives in blueberries improve insulin sensitivity in obese, insulin-resistant men and women. J Nutr. 2010;140:1764-1768.

23. Jennings A, Welch AA, Spector T, Macgregor A, Cassidy A. Intakes of anthocyanins and flavones are associated with biomarkers of insulin resistance and inflammation in women. J Nutr. 2014;144:202-208.

24. Inaguma T, Han J, Isoda H. Improvement of insulin resistance by cyanidin 3-glucoside, anthocyanin from black beans through the up-regulation of GLUT4 gene expression. BMC Proceedings. 2011;5 (Suppl 8): P21. 22 $2^{\text {nd }}$ European Society for Animal Cell Technology (ESACT) Meeting on Cell Based Technologies. Vienna, Austria. May 15-18, 2011.

25. Takikawa M, Inoue S, Horio F, Tsuda T. Dietary anthocyanin-rich bilberry extract ameliorates hyperglycemia and insulin sensitivity via activation of AMP-activated protein kinase in diabetic mice. $J$ Nutr. 2010;140:527-533.

26. Kurimoto $Y$, Shibayama $Y$, Inoue $S$, et al. Black soybean seed coat extract ameliorates hyperglycemia and insulin sensitivity via the activation of AMP-activated protein kinase in diabetic mice. J Agric Food Chem. 2013;61:5558-5564.

27. Mihaylova MM, Shaw RJ. The AMP-activated protein kinase (AMPK) signaling pathway coordinates cell growth, autophagy and metabolism. Nat Cell Biol. 2011;13:1016-1023.

28. Sasaki R, Nishimura N, Hoshino H, et al. Cyanidin 3-glucoside ameliorates hyperglycemia and insulin sensitivity due to downregulation of retinol binding protein 4 expression in diabetic mice. Biochem Pharmacol. 2007;74:1619-1627.
29. Wentworth JM, Naselli G, Brown WA, et al. Pro-inflammatory CD11c+CD206+ adipose tissue macrophages are associated with insulin resistance in human obesity. Diabetes. 2010;59:1648-1656.

30. Guo $H$, Ling W, Wang $Q$, et al. Effect of anthocyanin-rich extract from black rice (Oryza sativa L. indica) on hyperlipidemia and insulin resistance in fructose-fed rats. Plant Foods Hum Nutr. 2007;62:1-6.

31. Törrönen R, Sarkkinen E, Tapola N, Hautaniemi E, Kilpi K, Niskanen L. Berries modify the postprandial plasma glucose response to sucrose in healthy subjects. Br J Nutr. 2010;103:1094-1097.

32. Törrönen $R$, Kolehmainen M, Sarkkinen $E$, Mykkänen $H$, Niskanen L. Postprandial glucose, insulin, and free fatty acid responses to sucrose consumed with blackcurrants and lingonberries in healthy women. Am J Clin Nutr. 2012;96:527-533.

33. Törrönen R, Kolehmainen M, Sarkkinen E, Poutanen $K$, Mykkänen $H$, Niskanen L. Berries reduce postprandial insulin responses to wheat and rye breads in healthy women. J Nutr. 2013;143:430-436.

34. Jayaprakasam B, Olson LK, Schutzki RE, Tai M-H, Nair MG. Amelioration of obesity and glucose intolerance in high-fat-fed C57BL/6 mice by anthocyanins and ursolic acid in Cornelian cherry (Cornus mas). J Agric Food Chem. 2006;54:243-248.

35. Nizamutdinova IT, Jin YC, Chung Jl, et al. The anti-diabetic effect of anthocyanins in streptozotocin-induced diabetic rats through glucose transporter 4 regulation and prevention of insulin resistance and pancreatic apoptosis. Mol Nutr Food Res. 2009;53:1419-1429.

36. Sun CD, Zhang B, Zhang JK, et al. Cyanidin-3-glucoside-rich extract from Chinese bayberry fruit protects pancreatic $\beta$ cells and ameliorates hyperglycemia in streptozotocin-induced diabetic mice. JMed Food. 2012;15:288-298.

37. Adisakwattana S, Yibchok-Anun S, Charoenlertkul P, Wongsasiripat N. Cyanidin-3-rutinoside alleviates postprandial hyperglycemia and its synergism with acarbose by inhibition of intestinal a-glucosidase. J Clin Biochem Nutr. 2011;49:36-41.

38. Akkarachiyasit S, Charoenlertkul P, Yibchok-Anun S, Adisakwattana $S$. Inhibitory activities of cyanidin and its glycosides and synergistic effect with acarbose against intestinal a-glucosidase and pancreatic a-amylase. Int J Mol Sci. 2010;11:3387-3396.

39. Zhang L, Li J, Hogan S, Chung H, Welbaum GE, Zhou K. Inhibitory effect of raspberries on starch digestive enzyme and their antioxidant properties and phenolic composition. Food Chem. 2010;119:592-599.

40. Jayaprakasam B, Vareed SK, Olson LK, Nair MG. Insulin secretion by bioactive anthocyanins and anthocyanidins present in fruits. J Agric Food Chem. 2005;53:28-31. 